\title{
Estudo do Comportamento de Conectores Crestbond por meio de Simulação Numérica
}

Hermano de Sousa Cardoso ${ }^{1 *}$, Rodrigo Barreto Caldas ${ }^{1}$, Ricardo Hallal Fakury ${ }^{1}$ e Gustavo de Souza Veríssimo²

${ }^{1}$ Universidade Federal de Minas Gerais, Programa de Pós-Graduação em Engenharia de Estruturas, Av. Antônio Carlos, 6627 - Escola de Engenharia, Bloco I - 40 andar - Sala 4215- Pampulha - Belo Horizonte - MG - Brasil, hermanocardoso@hotmail.com, caldas@dees.ufmg.br, fakury@dees.ufmg.br

2 Departamento de Engenharia Civil, Universidade Federal de Viçosa, Av. P. H. Rolfs, s/n, Campus Universitário, Viçosa, MG, Brasil, gustavo@ufv.br

\section{Study of Behavior of Crestbond Connectors by Numerical Analysis}

\section{Resumo}

Os conectores de cisalhamento constituídos por chapas de aço com recortes regulares, nomeados como composite dowels, podem apresentar diversas geometrias, uma das quais caracteriza o conector Crestbond. Neste trabalho, é mostrado o comportamento desse conector quando utilizado de formas contínua e descontínua em vigas mistas a partir de simulações numéricas utilizando o software comercial Abaqus. Ao final, ficou constatado o surgimento de fissuras na linha de ação dos conectores e nas extremidades das lajes caracterizando a falha do concreto por cisalhamento. Constatou-se também que quando o conector é utilizado de forma contínua, a capacidade média de um componente (dowel) de concreto para resistir a esforços de cisalhamento permanece a mesma, independentemente do número de componentes.

Palavras-chave: vigas mistas de aço e concreto, conectores Crestbond, ensaios de cisalhamento, análise numérica, conectores em chapa.

\section{Abstract}

The shear connectors composed by steel plates with regular cutouts, known as composite dowels, may present different shapes, one of them is denominated as Crestbond. This study shows the behavior of this connector, when applied to composite beams both in continuously and discontinuous modes through numerical simulation by using the commercial software Abaqus. At the end, it was observed the appearance of cracks in the line of action of the connectors and at the outer slab region which leads the concrete shearing failure. It was also noted that whenever the connector is used continuously, the concrete dowel average strength to resist shearing loads remains constant, regardless the number of dowels.

Keywords: steel and concrete composite beams, Crestbond shear conectors, push-tests, numerical analysis, composite dowels.

\footnotetext{
* Autor correspondente
} 


\section{Introdução}

Nas duas últimas décadas, têm sido bastante estudados, em especial no Brasil e na Europa, conectores de cisalhamento constituídos por chapas de aço com recortes regulares, denominados genericamente na literatura em língua inglesa como composite dowels, por apresentarem dowels de aço (componentes de aço) e dowels de concreto (componentes de concreto) (Figura 1). Esses dispositivos podem ser utilizados de forma descontínua (nesse caso, o conector é denominado descontínuo - Figura 2a) ou contínua (conector contínuo - Figura 2b). Na Figura 2b pode-se observar, adicionalmente, uma das vantagens desse tipo de conector, que é a de permitir com facilidade o posicionamento de barras de aço da armadura entre suas aberturas.

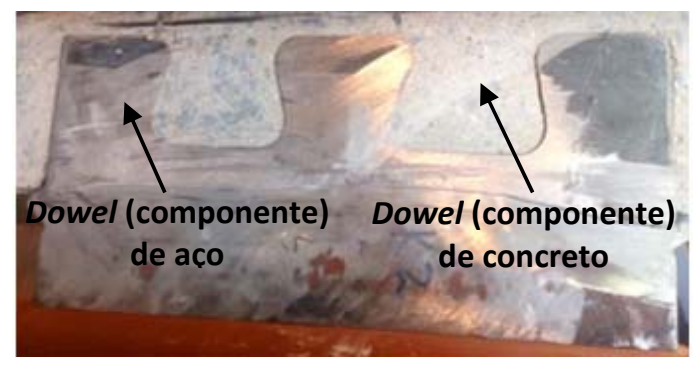

Figura 1 - Conector em chapa com recortes regulares.

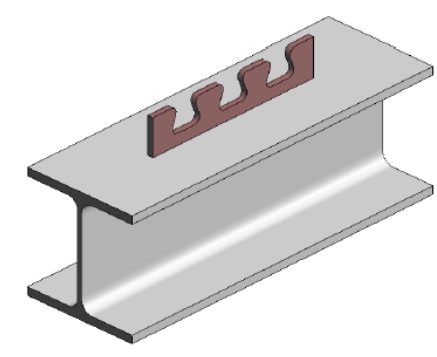

(a) Descontínua

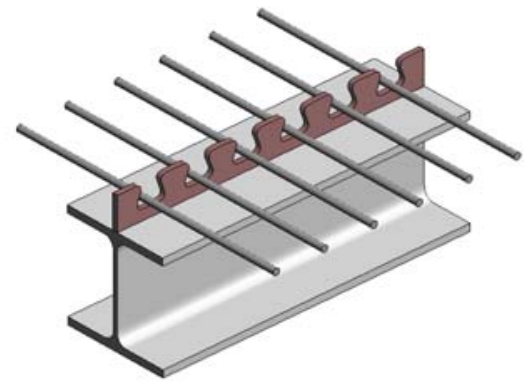

(b) Contínua (com armadura passante)

Figura 2 - Formas de utilização dos conectores (Veríssimo, 2007).

Os conectores de cisalhamento constituídos por chapas podem apresentar diversas geometrias de recortes, algumas das quais, com suas denominações, são mostradas na Figura 3. Grande parte dos estudos envolvendo esse tipo de conector foi realizado com o intuito de definir qual geometria conduz a uma maior capacidade resistente, mantendo características importantes para o projeto, como elevada rigidez em estadolimite de serviço e alta ductilidade em estado-limite último, além de baixo custo de fabricação. 


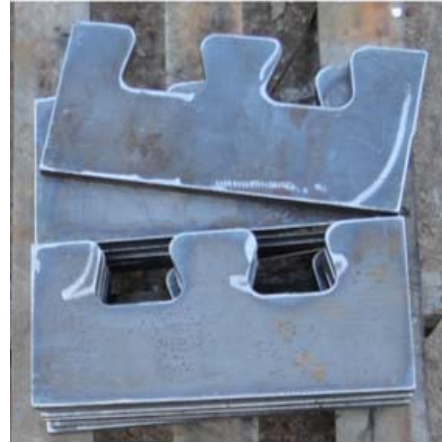

(a) Crestbond

(Cardoso, 2016)

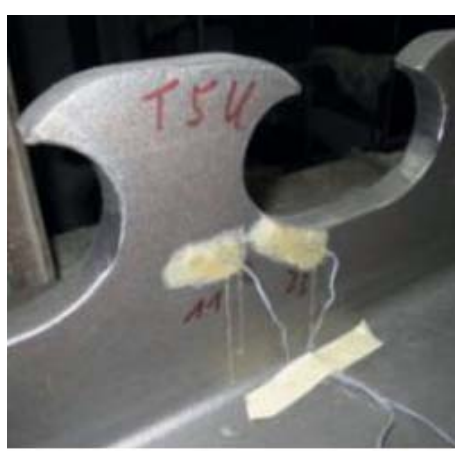

(b) clothoidal-shaped

(Berthellemy et al., 2011)

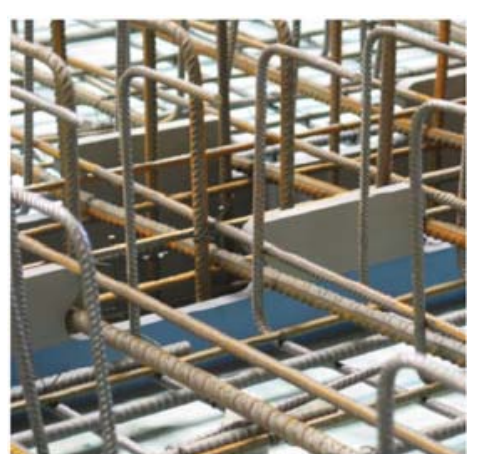

(c) puzzle-shaped

(Schmitt et al., 2004)

Figura 3-Algumas geometrias de conectores em chapas com recortes regulares.

A primeira publicação com a denominação de conector Crestbond (Figura 3a) ocorreu em 2006, descrevendo um estudo experimental desenvolvido por Veríssimo et al. (2006). Nesse mesmo ano, o projeto europeu Preco-Beam (Biegus e Lorenc, 2015) foi aprovado, sendo financiado pelo fundo Research Fund for Coal and Steel. Esse projeto estudou diversas geometrias de conectores, e com a sua finalização, foram publicados dois manuais de projeto: Preco-Beam (Seidl et al., 2013a) e Preco+ (Seidl et al., 2013b). Esses manuais apresentam prescrições para o dimensionamento dos conectores clothoid-shaped (Figura 3b) e puzzle-shaped (Figura 3c). Há uma forte perspectiva que as prescrições para essas duas geometrias sejam inclusas na próxima versão da norma europeia de estruturas mistas de aço e concreto (atual EN 1994-1-1:2004) ou dispostas na forma de um anexo suplementar (Feldmann et al., 2016).

Segundo Lorenc (2017), os conectores composite dowels foram empregados pela primeira vez em projetos de pontes na década passada, ao mesmo tempo que estudos sobre esse tema eram desenvolvidos. O autor ainda comenta que até no final de 2016, pelo menos 34 pontes utilizando conectores composite dowels foram construídas. Percebe-se assim, a importância do desenvolvimento contínuo de estudos no Brasil utilizando esses tipos de conectores e demonstrando ao mercado brasileiro a sua aplicabilidade.

O conector Crestbond permanece sendo bastante estudado, visando seu aprimoramento dimensional e definição do seu comportamento sob condições distintas. Diversos trabalhos têm sido realizados estudando essa geometria a partir de 2006 (Veríssimo et al., 2006; Veríssimo, 2007; Silva, 2011; Silva, 2013; Dutra, 2014, Aguiar, 2015; Petrauski, 2016). Mais recentemente, foram desenvolvidos estudos sobre 
o comportamento do conector Crestbond em situações específicas, como na região de introdução de forças de pilares mistos preenchidos com concreto em temperatura ambiente (Cardoso, 2016) e em temperatura elevada (Prado e Caldas, 2016).

Neste trabalho é discutido o comportamento dos conectores Crestbond quando aplicados em elementos de vigas mistas, a partir de análises numéricas efetuadas pelo Método dos Elementos Finitos com a utilização do Programa Abaqus (Hibitt et al., 2014). Para atingir esse objetivo, foi efetuada primeiro a calibração do modelo numérico considerando os modelos experimentais de ensaios de cisalhamento padrão realizados por Veríssimo (2007), com conectores descontínuos. Após a calibração, foi analisado o comportamento desses conectores e efetuadas análises também do comportamento dos conectores contínuos.

\section{Ensaios para a Caracterização da Capacidade Resistente do Conector}

A norma europeia de estruturas mistas de aço e concreto EN 1994-1-1:2004 apresenta os procedimentos para o ensaio de cisalhamento padrão (standard push test - Figura 4) para a caracterização de conectores a serem utilizados em vigas mistas de aço e concreto. Nesse ensaio, são adotados conectores de cisalhamento soldados em perfis $\mathrm{H}$ posicionados entre duas lajes de concreto.

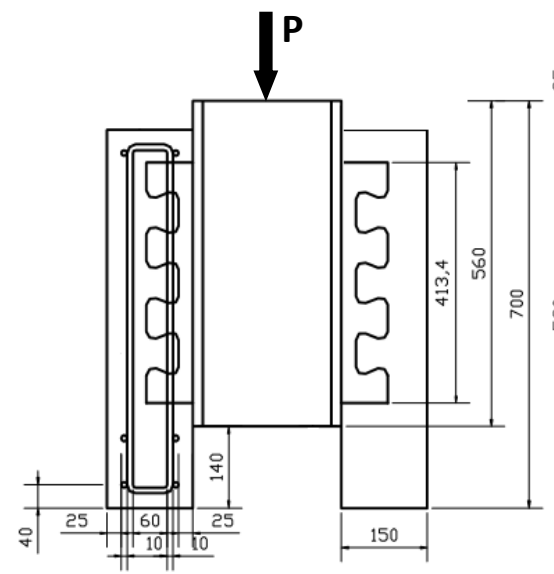

(a) vista frontal

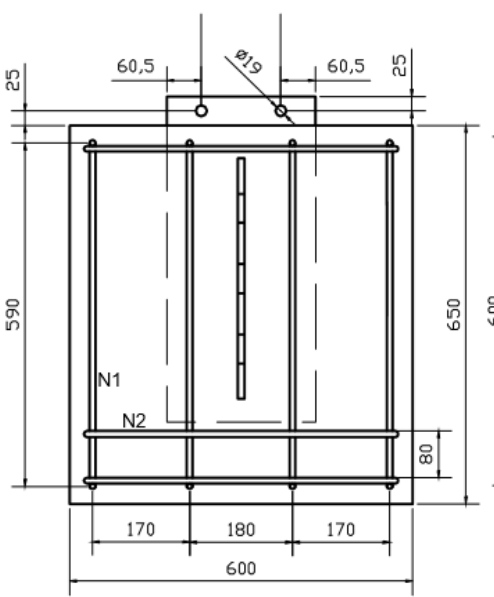

(b) vista lateral

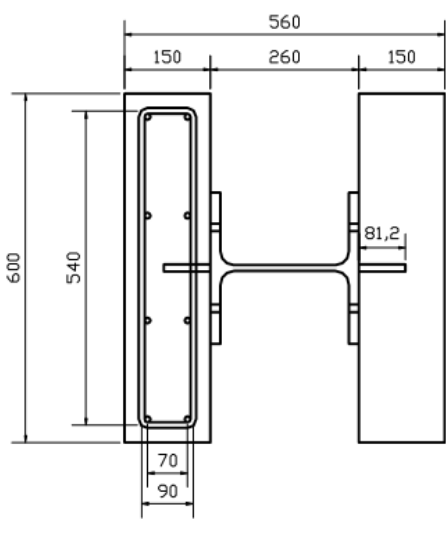

(c) vista superior

Figura 4 - Ensaio de cisalhamento padrão (standard push test) (adaptado de Veríssimo, 2007). Lorenc et al. (2010) propõem uma adaptação desse ensaio, na qual é eliminada a parcela de força resistida pela região frontal do conector nos ensaios, como se observa na Figura 5, aplicando-se um material de resistência desprezável, como uma camada de isopor. Ensaios com essa adaptação foram os utilizados no projeto Preco-Beam. Como 
o conector permite o corte simétrico, pode-se realizar o corte na alma de um perfil I ou $\mathrm{H}$ para obter o formato desejado do conector. Assim, com o procedimento de corte no perfil original, dispõem-se de dois novos perfis em formato de $\mathrm{T}$ e com o conector situado na extremidade da alma desses perfis. Posteriormente, as mesas dos dois perfis T são soldadas entre si, e os conectores são dispostos internamente nas duas lajes de concreto (Figura 5).

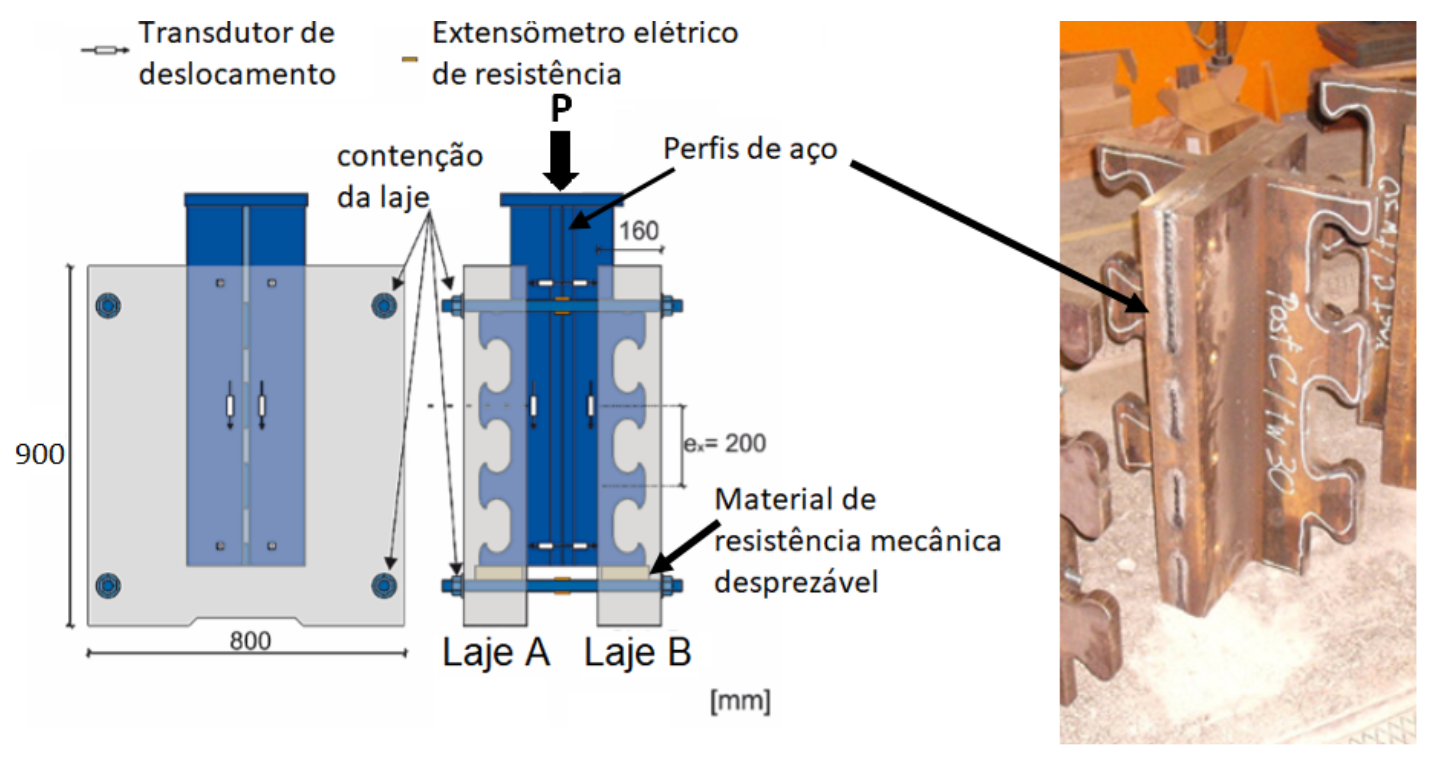

(a) ilustração do ensaio (adaptado

(b) perfil de aço e conector de Classen e Gallwoszus, 2016) (adaptado de Lorenc et al. 2014)

Figura 5 - Ensaio de cisalhamento adaptados para conectores contínuos.

Observando-se ainda a Figura 5, percebe-se que há também a contenção da laje impedindo o seu desprendimento em relação ao perfil de aço. O uso dessa restrição é aconselhada para simular o uso dos conectores em vigas mistas de pontes, nas quais além de haver a continuidade da laje de concreto e do conector, é utilizada, na maioria dos casos, alta taxa de armadura (Figura 3c).

\section{Comportamento de Conectores Crestbond em Ensaios de Cisalhamento Padrão}

Neste item são descritos os ensaios de cisalhamento padrão com conectores Crestbond de geometria CR56b e com conectores constituídos por chapas sem furos, realizados por Veríssimo (2007), mostrados na Figura 6. Na designação CR56b, 56 indica o diâmetro em milímetros da circunferência inscrita no componente de concreto, e b indica uma versão do conector, na qual os componentes de aço intermediários e externos possuem as 
larguras mínimas iguais (na Figura 6a, essas larguras são iguais a $50 \mathrm{~mm}$ ). Os conectores constituídos por chapas sem aberturas tinham dimensões externas iguais às dos conectores Crestbond, e foram designados como CR 56b-SF.

CR56b

CR 56b-SF

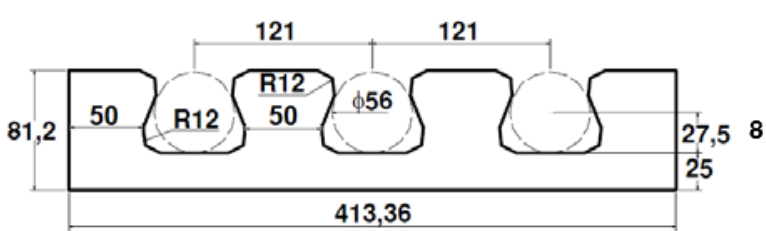

(a) conector Crestbond CR56b

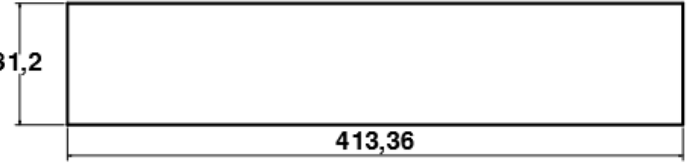

(b) conector constituído por chapa CR 56b-SF

Figura 6 - Conectores ensaiados por Veríssimo (2007).

Essa parte do programa experimental incluiu ao todo 16 modelos, subdivididos em duas séries: B e C. As características e propriedades dos modelos dessas séries são apresentadas na Tabela 1. Como pode-se observar, essas séries eram diferenciadas pela resistência à compressão do concreto $\left(f_{c}\right)$. Na série $B$, essa resistência nos dias dos ensaios variou entre $25 \mathrm{MPa}$ e $30 \mathrm{MPa}$. Na série $\mathrm{C}$, variou entre $45 \mathrm{MPa}$ e $50 \mathrm{MPa}$. Nas duas séries existiam quatro variações de modelos, sendo três com conectores CR56b e uma com conectores CR56b-SF. As variações com conectores Crestbond se deviam à utilização de diferentes taxas de armadura passante nos componentes de concreto: sem armadura, com uma barra de armadura de $10 \mathrm{~mm}$ e com uma barra de armadura de $12 \mathrm{~mm}$. Nota-se, na Tabela 1, onde $\phi$ indica o diâmetro da barra da armadura, que os modelos agrupados em pares (ex: B1 e B2, C1 e C2, B3 e B4, etc.) apresentam as mesmas características, podendo-se considerá-los pares de modelos semelhantes.

Tabela 1 - Características e propriedades dos modelos das séries B e C.

\begin{tabular}{|c|c|c|c|c|c|c|c|}
\hline \multicolumn{3}{|c}{ Série B } & \multicolumn{5}{c|}{ Série C } \\
\hline Modelo & Designação & $\begin{array}{c}f_{c} \\
(\mathrm{MPa})\end{array}$ & $\begin{array}{c}\Phi \\
(\mathrm{mm})\end{array}$ & Modelo & Designação & $\begin{array}{c}f_{c} \\
(\mathrm{MPa})\end{array}$ & $\begin{array}{c}\Phi \\
(\mathrm{mm})\end{array}$ \\
\hline B1 & CR56b & 26,6 & 0 & C1 & CR56b & 46,9 & 0 \\
\hline B2 & CR56b & 26,6 & 0 & C2 & CR56b & 48,1 & 0 \\
\hline B3 & CR56b & 27,2 & 10 & C3 & CR56b & 49,1 & 10 \\
\hline B4 & CR56b & 26,9 & 10 & C4 & CR56b & 48,7 & 10 \\
\hline B5 & CR56b & 28,5 & 12 & C5 & CR56b & 48,7 & 12 \\
\hline B6 & CR56b & 24,8 & 12 & C6 & CR56b & 45,9 & 12 \\
\hline B7 & CR56b-SF & 28,3 & 0 & C7 & CR56b-SF & 49,4 & 0 \\
\hline B8 & CR56b-SF & 24,8 & 0 & C8 & CR56b-SF & 49,7 & 0 \\
\hline
\end{tabular}


Algumas características comuns a todos os modelos podem ser citadas:

- os conectores e os perfis $\mathrm{H}$ possuíam resistência ao escoamento $\left(f_{y}\right)$ e resistência à ruptura $\left(f_{u}\right)$ iguais $324 \mathrm{MPa}$ e $489 \mathrm{MPa}$, respectivamente;

- os modelos possuíam barras de armadura de diâmetro de $10 \mathrm{~mm}$ acima e abaixo dos conectores - ver barras designadas como N2 na Figura 4;

- as espessuras do conector e da laje de concreto eram iguais a $12 \mathrm{~mm}$ e $150 \mathrm{~mm}$, respectivamente;

- os perfis H possuíam altura e largura das mesas de $260 \mathrm{~mm}$, espessura das mesas e das almas de $17,5 \mathrm{~mm}$ e $10 \mathrm{~mm}$ respectivamente.

\section{Modelo Numérico}

A modelagem numérica foi realizada através do software comercial de elementos finitos Abaqus (Hibitt et al., 2014). Os modelos foram simulados tomando-se apenas um quarto da sua geometria, devido à dupla simetria, como pode ser observado na Figura 7a. 0 método de convergência utilizado foi o Dynamic Implicit, geralmente utilizado em problemas dinâmicos, podendo ser empregado também em problemas quase-estáticos. O processo interativo se deu por controle de deslocamento, prescrevendo um deslocamento de magnitude de valor $U$, como pode-se observar na extremidade superior do perfil $\mathrm{H}$ na Figura 7b. Os valores de deslocamentos prescritos foram iguais aos descolamentos máximos obtidos nos ensaios experimentais.
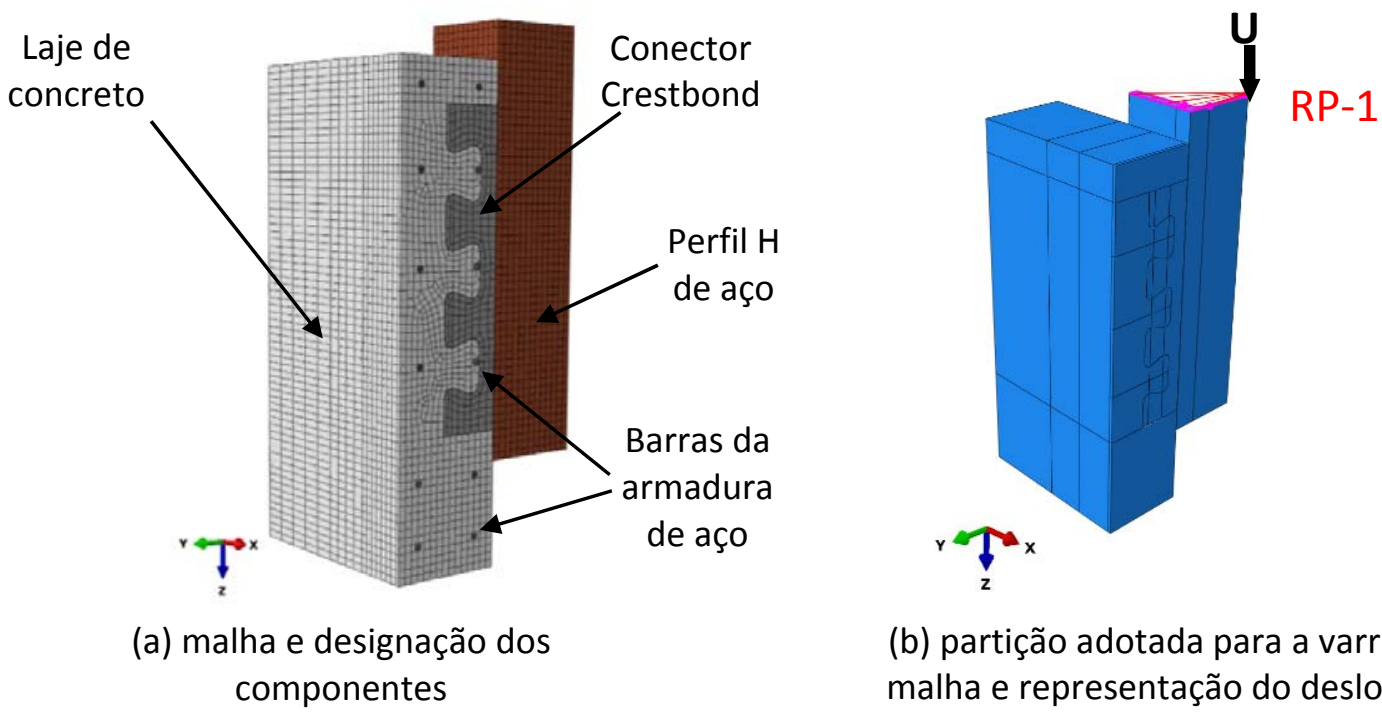

(b) partição adotada para a varredura da malha e representação do deslocamento controlado

Figura 7 - Modelos numéricos de ensaios de cisalhamento utilizando conectores Crestbond. 
A laje de concreto, o perfil de aço e os conectores de cisalhamento foram modelados com elementos hexaédricos do tipo C3D8. Para as barras de armadura envolvidas pelo concreto, foram utilizados elementos de viga B31. O contato entre concreto, perfil de aço e conectores de cisalhamento foi simulado através de interações face a face. Baseando-se na calibração numérica realizada nos estudos de Aguiar (2015), para o contato entre o Crestbond e o concreto foi adotado um coeficiente de atrito estático $(\mu)$ igual a 0,5. Nas regiões de contato restantes, não foi adotado atrito. Para as barras de armadura de aço, foi utilizada a ferramenta embedded, que permite que haja uma aderência completa delas com o concreto. Na Figura 8 são representadas as condições de contorno adotadas nos modelos.

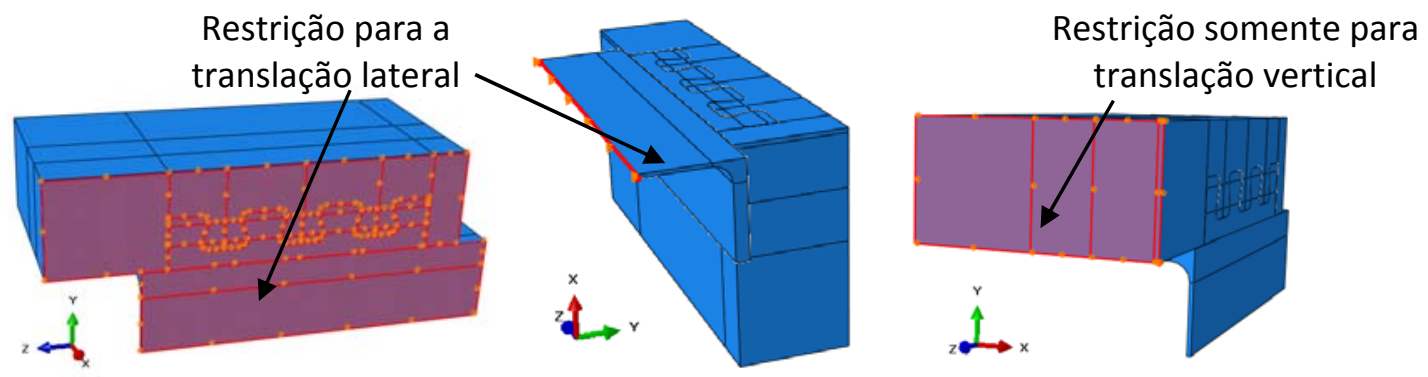

Figura 8 - Condições de contorno adotadas para o modelo numérico.

O diagrama de tensão versus deformação, que representa a lei constitutiva dos conectores Crestbond e do perfil de aço, é ilustrado na Figura 9a. Esse diagrama foi utilizado no estudo de Aguiar (2015), e possui um trecho elástico seguido de um patamar de escoamento e de uma região de encruamento e, posteriormente, um descarregamento simulando a ruptura do material. Para as barras de aço da armadura presentes na laje de concreto, um comportamento elastoplástico perfeito foi adotado, como pode ser observado na Figura 9b.

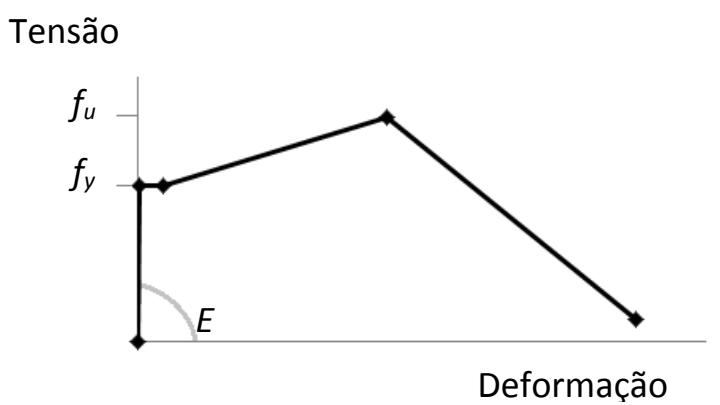

(a) conector Crestbond e perfil de aço

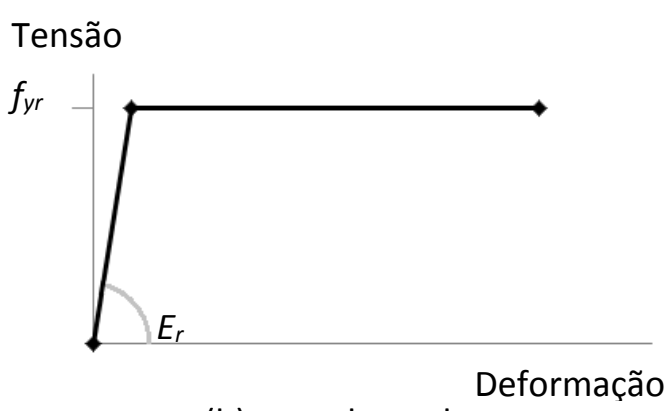

(b) armaduras de aço

Figura 9 - Representação das leis constitutivas. 
Para levar em conta o efeito de dano e do confinamento no núcleo de concreto, foi utilizado o modelo constitutivo Concrete Damage Plasticity, que permite simular a perda de rigidez do concreto após atingir o ponto de sua resistência máxima. Nesse modelo constitutivo foram adotados os seguintes parâmetros: ângulo de dilatância $(\psi)$ igual a $28^{\circ}$; razão entre as resistências à compressão nos estados biaxial e uniaxial $\left(\sigma_{b 0} / \sigma_{c 0}\right)$ igual a 1,16; razão entre o segundo invariante de tensão no meridiano de tração e o segundo invariante de tensão no meridiano de compressão $\left(K_{c}\right)$ igual a $2 / 3$; viscosidade $\left(\mu_{v i s}\right)$ igual a $5 \times 10^{-5}$, e; excentricidade $(\epsilon)$ igual a 0,1 . Uma descrição sucinta dos parâmetros supracitados pode ser encontrada na documentação técnica do programa (Hibitt et al., 2014).

O comportamento do concreto à compressão foi representado através da lei constitutiva representada pelo diagrama ilustrado na Figura 10a (o valor de $40 \mathrm{MPa}$ é apenas uma exemplificação). Nesse diagrama, considera-se que o concreto se comporta linearmente até atingir $40 \%$ do valor da resistência à compressão média $f_{c m}$. Posteriormente, em cor vermelha, é utilizada a formulação proposta pela norma europeia EN 1992-1-1:2004. Contudo, a formulação proposta pela norma europeia se limita a uma deformação última de $\varepsilon_{c u 1}$, correspondente à tensão $f_{c u 1}$, no ponto $\mathrm{D}$. Entretanto, nas estruturas mistas em que se utilizam conectores de cisalhamento, podem ocorrer elevadas deformações por esmagamento na região do concreto em contato com os conectores. Dessa maneira, a resistência do concreto pode ser superestimada caso não sejam consideradas deformações superiores a $\varepsilon_{c u 1}$. Para contornar essa situação, foi utilizada uma extensão para o trecho de curva obtida com a formulação da norma EN 1992-1-1:2004, conforme proposta de Pavlović et al. (2013). O comportamento do concreto à tração foi representado através de curvas de tensão versus tamanho de abertura por fissura fictícia. O primeiro ponto dessa curva tem como tensão a resistência média do concreto à tração $\left(f_{c t m}\right)$, a partir do qual é representada a perda de resistência devida ao processo de fissuração. Na Figura 10b é apresentado um diagrama com uma curva com tensão $f_{c t m}$ igual a 3,0 MPa (valor de $f_{c t m}$ escolhido para exemplificação) e com abertura de fissura crítica $\left(w_{c}\right)$ igual a 1,0 $\mathrm{mm}$, valor que define o tamanho necessário de abertura de fissura para que o concreto tenha resistência nula $\left(f_{c t m}=0\right)$. Por motivos de convergência, o último ponto da curva é estabelecido quando 
a tensão é igual a $5 \%$ de $f_{c t m}$. Neste trabalho, após a calibração com os modelos experimentais de Veríssimo (2007), adotou-se para $w_{c}$ o valor de 1,0 mm. Os valores de $f_{c t m}$ foram estimados a partir dos valores de $f_{c m}$ (obtidos em ensaios de compressão de corpo de prova), conforme a Tabela 3.1 da norma EN 1992-1-1:2004.

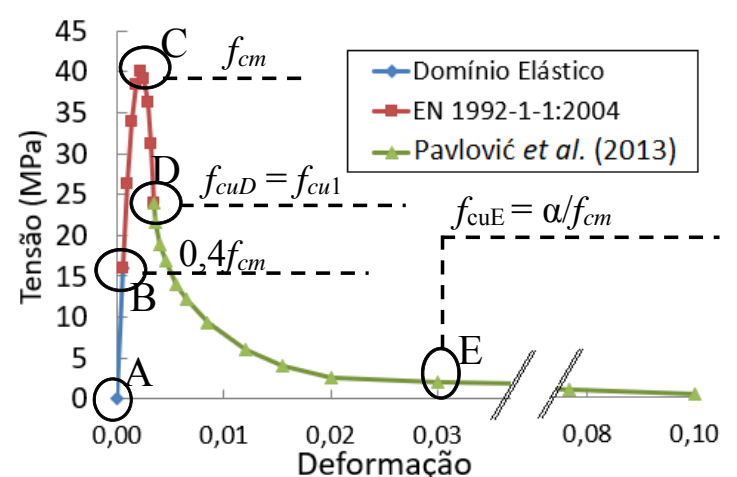

(a) comportamento à compressão $\operatorname{com} f_{c m}$ igual a $40,0 \mathrm{MPa}$

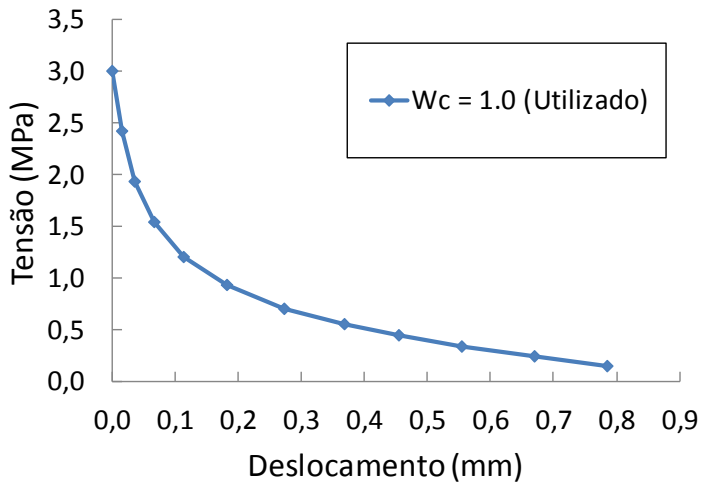

(b) comportamento à tração $\operatorname{com} f_{c t m}$ igual a 3,0 MPa.

Figura 10 - Diagramas tensão versus deformação para material concreto.

As curvas de tensão versus tamanho de abertura por fissura fictícia que estabelecem a lei constitutiva do concreto à tração foram obtidas por meio de uma função polinomial cúbica de Bézier, representada por:

$$
B(t)=\left[\frac{w}{w_{c}}(t), \frac{\sigma_{t}}{f_{c t m}}(t)\right]=(1-t)^{3} P_{0}+3(1-t)^{2} t P_{1}+3(1-t) t^{2} P_{2}+t^{3} P_{3} \therefore t \in[0,1]
$$

onde $t$ é um parâmetro que varia de 0 a 1,0, w é largura em milímetros da abertura por fissura fictícia, $w_{c}$ é a abertura de fissura crítica, $\sigma_{t}$ é a tensão de tração, $f_{c t m}$ é a resistência do concreto à tração e $P_{0}, P_{1}, P_{2}$ e $P_{3}$ são parâmetros de ajuste da curva. Neste trabalho, foram adotados os valores desses parâmetros de ajustes sugeridos por Kim e Nguyen (2010), e que são os seguintes:

$$
B(t)=\left[\frac{w}{w_{c}}(t)\right],\left\{\begin{array}{l}
P_{0} \\
P_{1} \\
P_{2} \\
P_{3}
\end{array}\right\}=\left\{\begin{array}{c}
0 \\
0,05 \\
0,1 \\
1,0
\end{array}\right\} ; B(t)=\left[\frac{\sigma}{f_{c t m}}(t)\right],\left\{\begin{array}{l}
P_{0} \\
P_{1} \\
P_{2} \\
P_{3}
\end{array}\right\}=\left\{\begin{array}{c}
1,0 \\
0,3 \\
0,2 \\
0
\end{array}\right\}
$$

O programa Abaqus (Hibitt et al., 2014) permite que se defina uma resposta de dano para uma melhor simulação do comportamento pós-pico do concreto. As variáveis de dano são definidas como $D_{c}=1-\sigma_{c} / f_{c m}$ e $D_{t}=1-\sigma_{t} / f_{c t m}$, estando correlacionadas com a deformação do concreto submetido à compressão e com a largura por abertura de fissura, respectivamente. 


\section{Análise Numérica de Ensaios de Cisalhamento Padrão com Conectores Crestbond}

Nas simulações realizadas neste trabalho, foram adotadas as características mecânicas e dimensões médias dos modelos experimentais ensaiados por Veríssimo (2007), as quais foram retratadas no Item 3. Na Tabela 2 são dispostas as forças máximas experimentais médias $\left(P_{u, \text { Exp }}\right)$, juntamente com o valor da resistência média do concreto à compressão $\left(f_{c m}\right)$, e as forças numéricas $\left(P_{u, N u m}\right)$. Na última coluna é fornecida a razão entre as forças $P_{u, N u m} / P_{u, E x p}$. Na Figura 11 são apresentados diagramas comparando as curvas força por conector versus deslizamento relativo de modelos experimentais (Veríssimo, 2007) e numéricos deste trabalho. Os modelos B7-B8 e C7-C8 serviram para a investigação da parcela de força resistida pela parte frontal do conector isoladamente. Ao avaliar os resultados, constata-se que a modelagem numérica demonstrou resultados bastante próximos aos obtidos experimentalmente.

Tabela 2 - Comparação entre os resultados experimentais e numéricos.

\begin{tabular}{|c|c|c|c|c|c|}
\hline $\begin{array}{c}\text { Modelo } \\
\text { Experimental }\end{array}$ & $\begin{array}{c}P_{u, E \times p} \\
(\mathrm{kN}) \\
\text { Valor médio }\end{array}$ & $\begin{array}{c}f_{c m} \\
(\mathrm{MPa}) \\
\text { Valor médio }\end{array}$ & $\begin{array}{l}\text { Modelo } \\
\text { Numérico }\end{array}$ & $\begin{array}{c}P_{u, N u m} \\
(k N)\end{array}$ & $\frac{P_{u, \text { Num }}}{P_{u, \text { Exp }}}$ \\
\hline B1 & \multirow{2}{*}{301,33} & \multirow{2}{*}{26,60} & \multirow{2}{*}{ B1-B2 } & \multirow{2}{*}{296,89} & \multirow{2}{*}{0,99} \\
\hline B2 & & & & & \\
\hline B3 & \multirow{2}{*}{362,30} & \multirow{2}{*}{27,05} & \multirow{2}{*}{ B3-B4 } & \multirow{2}{*}{331,11} & \multirow{2}{*}{0,91} \\
\hline B4 & & & & & \\
\hline B5 & \multirow{2}{*}{374,95} & \multirow{2}{*}{26,65} & \multirow{2}{*}{ B5-B6 } & \multirow{2}{*}{326,29} & \multirow{2}{*}{0,87} \\
\hline B6 & & & & & \\
\hline B7 & \multirow{2}{*}{180,65} & \multirow{2}{*}{26,55} & \multirow{2}{*}{ B7-B8 } & \multirow{2}{*}{131,21} & \multirow{2}{*}{0,73} \\
\hline B8 & & & & & \\
\hline $\mathrm{C} 1$ & \multirow{2}{*}{369,40} & \multirow{2}{*}{47,50} & \multirow{2}{*}{$\mathrm{C} 1-\mathrm{C} 2$} & \multirow{2}{*}{416,54} & \multirow{2}{*}{1,13} \\
\hline $\mathrm{C2}$ & & & & & \\
\hline C3 & \multirow{2}{*}{500,15} & \multirow{2}{*}{48,90} & \multirow{2}{*}{ C3-C4 } & \multirow{2}{*}{456,00} & \multirow{2}{*}{0,91} \\
\hline C4 & & & & & \\
\hline $\mathrm{C} 5$ & \multirow{2}{*}{480,90} & \multirow{2}{*}{47,30} & \multirow{2}{*}{ C5-C6 } & \multirow{2}{*}{460,86} & \multirow{2}{*}{0,96} \\
\hline C6 & & & & & \\
\hline C7 & \multirow{2}{*}{216,55} & \multirow{2}{*}{49,55} & $\mathrm{C} 7-\mathrm{C} 8$ & 20020 & 0.92 \\
\hline C8 & & & & & \\
\hline & & & & Média & 0,93 \\
\hline
\end{tabular}

Analisando os diagramas apresentados na Figura 11, nota-se que as forças máximas experimentais e numéricas foram consideravelmente menores nos modelos com conectores formados por chapas sem aberturas (CR 56b-SF, ou seja, modelos B7, B8, C7 
e C8). Nesses conectores, há somente a parcela de resistência decorrente da sua capacidade frontal. Nos conectores Crestbond (CR 56b), além dessa parcela de resistência, há aquela proporcionada pelos componentes de concreto.
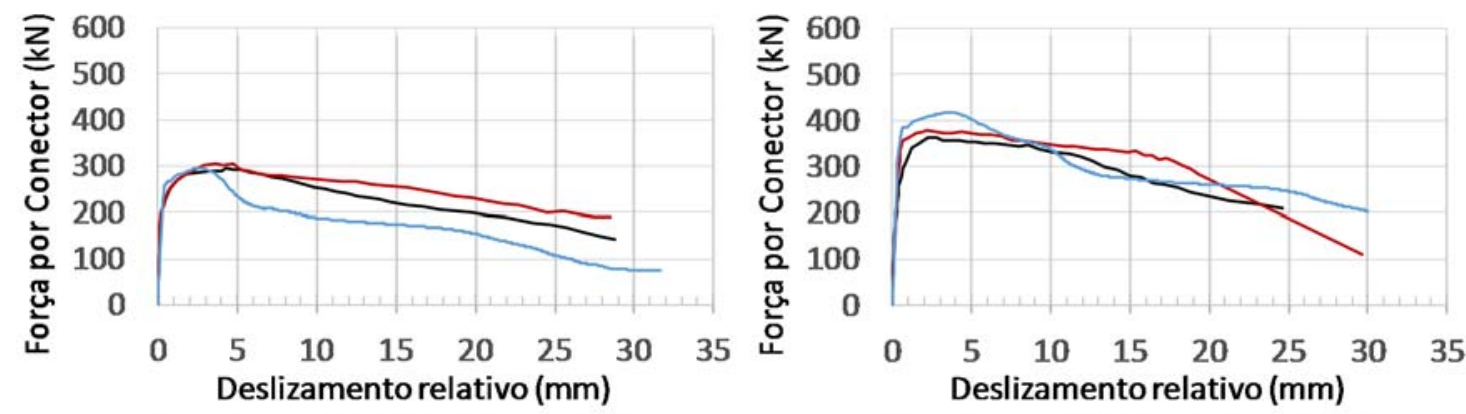

-Experimental B1 (Veríssimo, 2007)

-Experimental B2 (Veríssimo, 2007)

- Numérico B1-B2

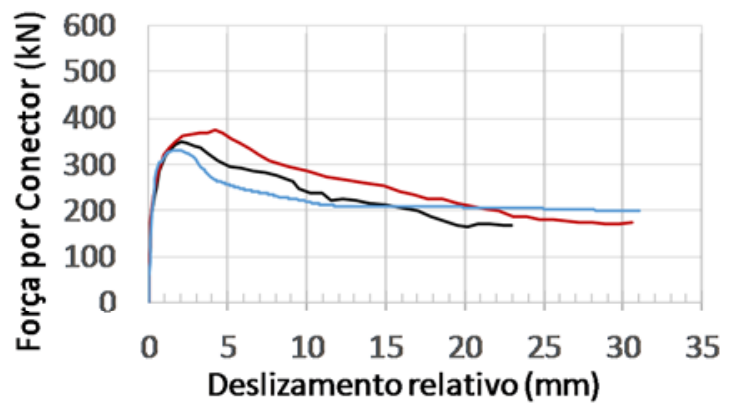

-Experimental B3 (Veríssimo, 2007)

-Experimental B4 (Veríssimo, 2007)

- Numérico B3-B4

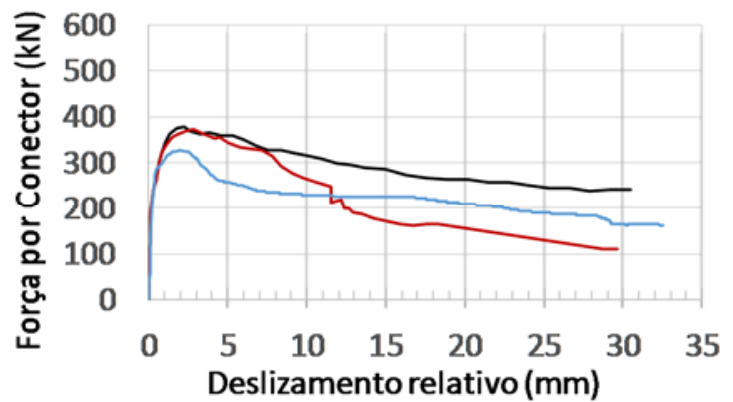

-Experimental B5 (Veríssimo, 2007)

-Experimental B6 (Veríssimo, 2007)

- Numérico B5-B6

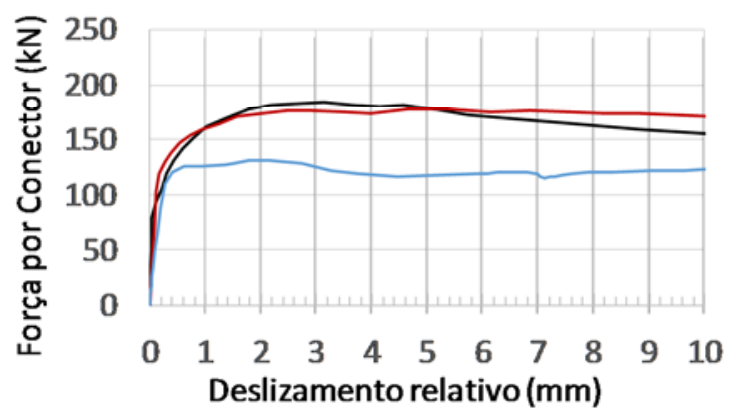

-Experimental B7 (Veríssimo, 2007)

- Experimental B8 (Veríssimo, 2007)

- Numérico B7-B8 (Veríssimo, 2007)

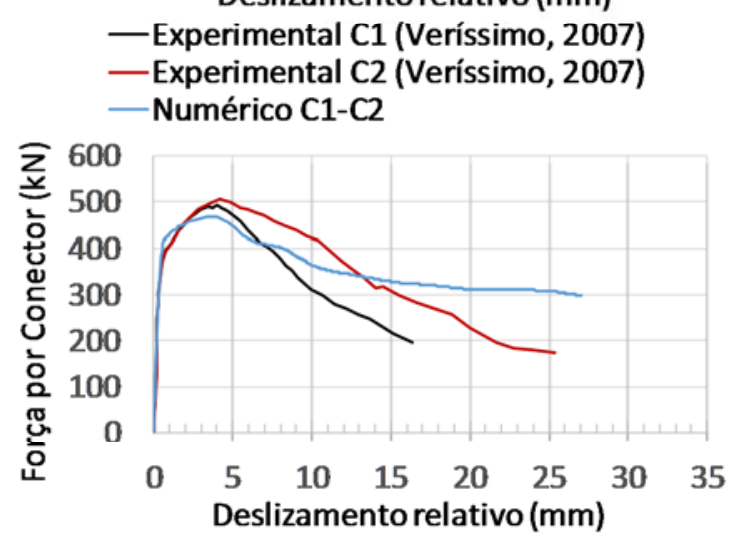

-Experimental C3 (Veríssimo, 2007)

-Experimental C4 (Veríssimo, 2007)

- Numérico C3-C4

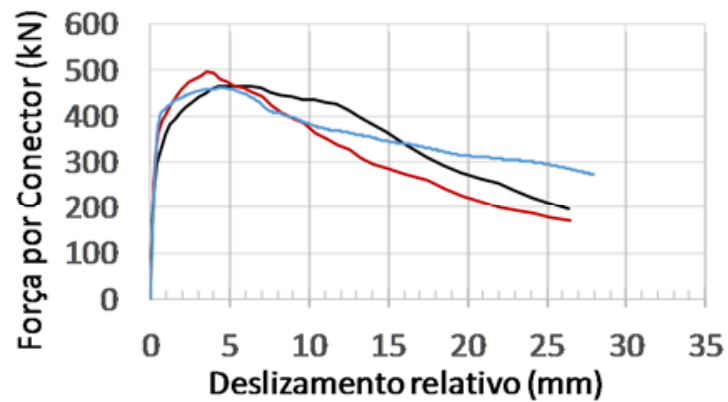

-Experimental C5 (Veríssimo, 2007)

—Experimental C6 (Veríssimo, 2007)

- Numérico C5-C6

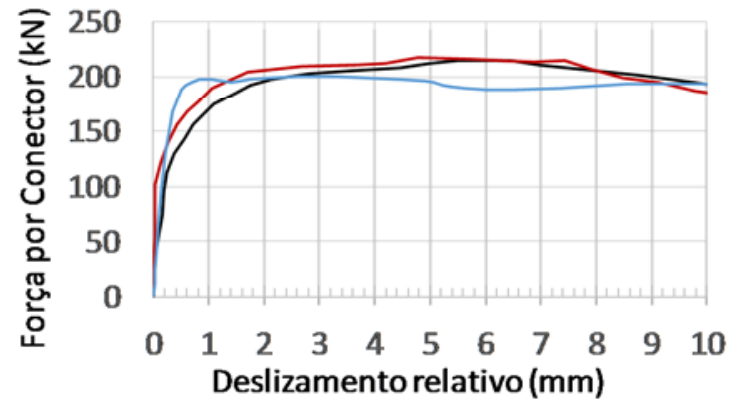

-Experimental C7 (Veríssimo, 2007)

-Experimental C8 (Veríssimo, 2007)

- Numérico $\mathrm{C7}$-C8

Figura 11 - Comparação entre curvas de força por conector versus deslizamento relativo. 
Veríssimo (2007) menciona que o modo de fissuração das lajes foi semelhante em todos os seus modelos ensaiados, com fissuras localizadas na linha de ação dos conectores e nas extremidades das lajes (Figura 12a). Além disso, havia um desprendimento de concreto em formato de cunha na região inferior da laje, logo abaixo do conector (Figura 12b). Todas essas observações foram constatadas nas simulações numéricas realizadas neste trabalho, como pode se observar nas Figuras 12c e 13b. Nessas figuras, o dano à tração no concreto da laje é representado pela varável DAMAGET, com cada coloração representando uma escala de dano indicada na legenda. Para esta variável, o valor 0 indica nenhum dano no material à tração e, o valor 1, o dano máximo à tração. A representação dessas variáveis ocorre em um dado incremento da análise, na qual o deslizamento relativo é próximo aos deslizamentos máximos obtidos nos ensaios experimentais (Figura 11), a fim de se obter uma melhor comparação entre deformação final dos modelos experimentais e numéricos.

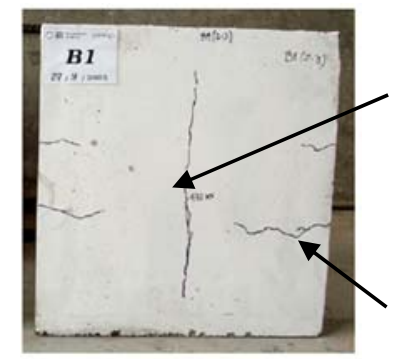

(a) vista lateral externa da laje (Veríssimo, 2007)

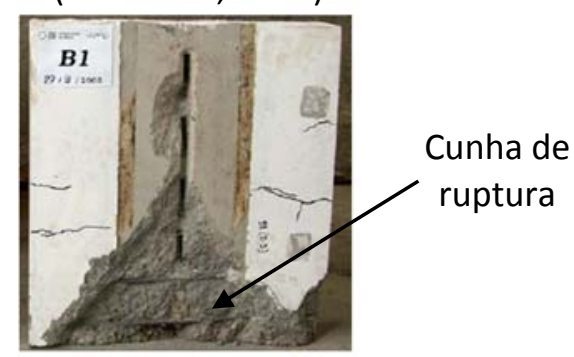

(b) vista lateral externa da laje (Veríssimo, 2007) da laje
Fissuras na linha de ação do conector

Fissuras na extremidade

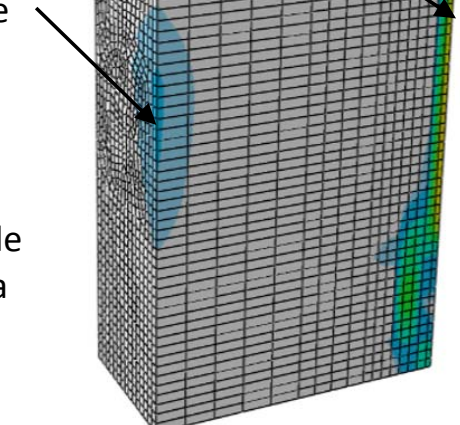

(c) varável DAMAGET no instante em que o deslizamento relativo é igual a $28,61 \mathrm{~mm}$

Figura 12 - Padrão de fissuração nas lajes de concreto nos modelos experimentais B1 e numérico B1-B2.

Medberry e Shahrooz (2002) realizaram ensaios de cisalhamento padrão com conectores Perfobond, e observaram o mesmo fenômeno de desprendimento de concreto em formato de cunha na região inferior da laje. Segundo os autores, na região frontal do conector, atuam além de esforços de compressão, esforços de tração. Medberry e Shahrooz (2002), em seu estudo, esquematizam a distribuição das tensões 
de tração na região abaixo dos conectores, como pode ser observado na Figura 13a. Como nessa região não há contenção da laje de concreto pelo perfil $\mathrm{H}$, há o desprendimento de uma região de concreto após um estágio avançado de fissuração. 0 fenômeno de desprendimento de uma parcela do volume de concreto da laje também é denominado pry-out. Na Figura 13b, é ilustrado o modelo numérico C1-C2, para um deslizamento de $27,69 \mathrm{~mm}$, muito superior ao deslocamento correspondente à força máxima (Figura 11). Logo, pode-se considerar esse desprendimento como um estágio pós-crítico.

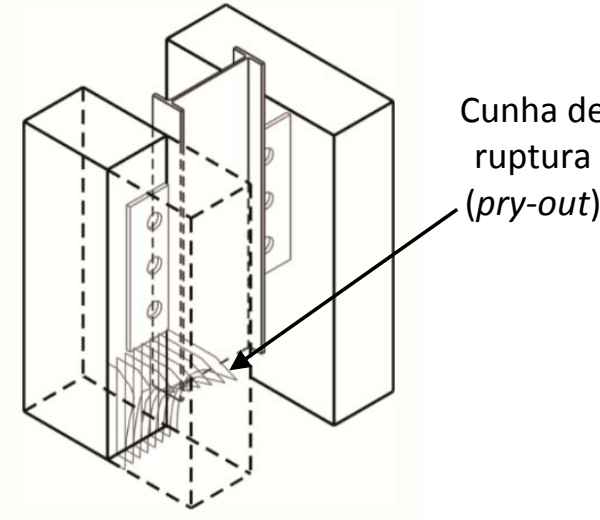

(a) ensaios com conectores Perfobond (Medberry e Shahrooz, 2002)

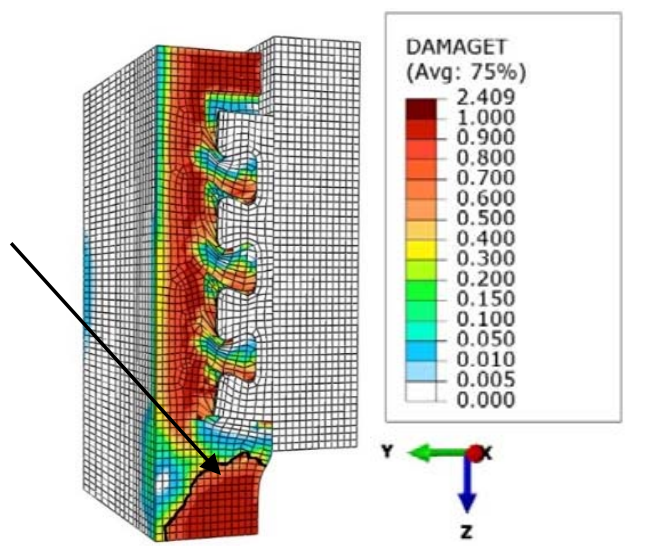

(b) Modelo C1-C2 no momento em que o deslizamento relativo é igual a $27,69 \mathrm{~mm}$

Figura 13 - Pry-out na região inferior da laje de concreto.

Veríssimo (2007) destaca que o primeiro componente de aço (ou dente frontal) dos conectores sofreu maior deformação, sendo que nos outros componentes de aço não se observou uma deformação significativa. Na Figura 14 são apresentadas as deformadas dos conectores do modelo experimental B1-B2, após o desmonte. Nas Figuras 15a e 15b são representadas as tensões de von Mises no conector do modelo numérico B1-B2. Na Figura 15a é ilustrado o estado de tensão correspondente ao incremento em que a solicitação no conector é máxima, observando-se que o escoamento só ocorre no primeiro componente de aço. Na legenda são representadas as tensões verdadeiras $f_{y}$ e $f_{u}$, iguais a $324,525 \mathrm{MPa}$ e $568,218 \mathrm{MPa}$, respectivamente.

A solicitação máxima do primeiro dente do conector ocorre quando o deslizamento relativo é igual a $19,30 \mathrm{~mm}$, que se manifesta ao se atingir a força máxima do modelo (Figura 11). Após esse estágio, as tensões de von Mises começam a diminuir, devido ao desprendimento do conector da laje (Figura 15b), efeito este conhecido como uplift, o 
qual também foi observado nos modelos ensaiados por Veríssimo (2007). Na Figura 15c são ilustrados os deslocamentos nodais na direção y no último incremento da análise numérica com deslizamento relativo igual a 31,67 $\mathrm{mm}$. Nota-se, assim, um significativo desprendimento da laje em relação ao perfil $\mathrm{H}$ de aço após o modelo atingir sua capacidade resistente máxima.

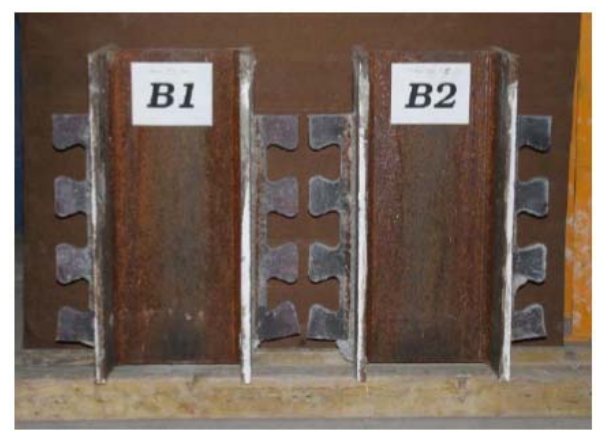

Figura 14 - Modelos experimentais B1 eB2 com Crestbond após ensaio (Veríssimo, 2007).

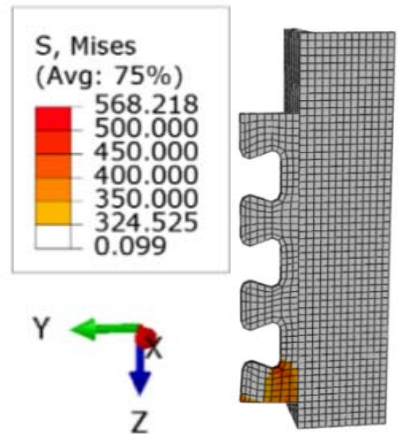

(a) Tensões de von Mises a um deslizamento de 19,3 mm

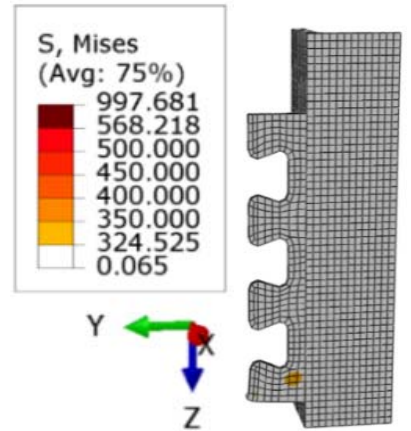

(b) Tensões de von Mises a um deslizamento de 28,6 mm

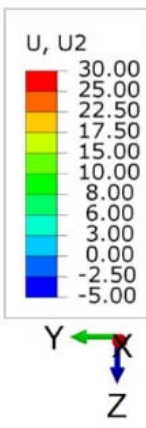

Desprendimento da

laje (uplift)

(c) deslocamentos na direção transversal a um deslizamento relativo de $31,67 \mathrm{~mm}$

Figura 15 - Análise do modelo numérico B1-B2.

Nas simulações foi observado o cisalhamento das lajes de concreto como estado-limite último. Segundo Kraus e Wurzer (1997) o componente de concreto apresenta duas regiões de comportamentos distintos. Uma primeira região sujeita a um estado triaxial de tensões de compressão em que o concreto é esmagado, e uma segunda região em que atua tanto esforços de tração quanto de compressão (Figura 16c). Essas observações foram constatadas na modelagem numérica. As Figuras 16a e 16b ilustram o modelo numérico B1-B2 quando submetido à força máxima atingida, igual a 296,9kN. O valor de 1,0 para a variável DAMAGEC, como na variável DAMAGET, representa o dano máximo, porém, nesse caso em relação aos esforços de compressão. Assim, observando-se a Figura 16a, nota-se que as duas regiões que constituem o componente 
de concreto apresentam dano máximo à compressão. Nota-se ainda que a fissuração se estende até a superfície da laje, na linha de ação do conector Crestbond (figuras 12c, $13 b$ e $16 b)$.

Região de concreto esmagada e sob altas

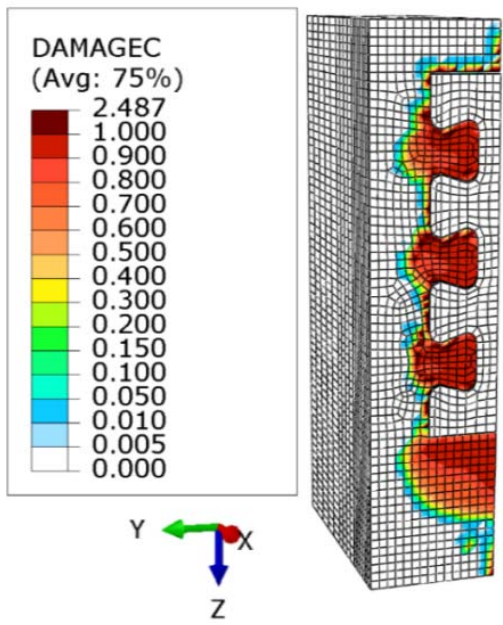

(a) variável DAMAGEC no modelo B1-B2 no incremento de força

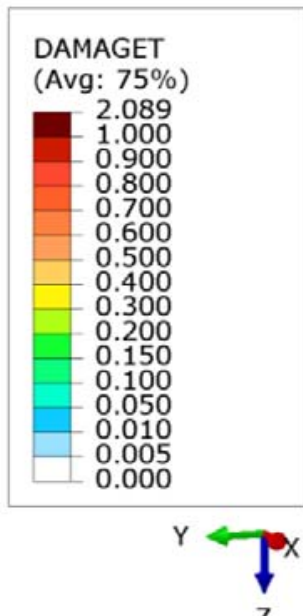

(b) variável DAMAGET no modelo B1-B2 no incremento de força máxima

tensões de confinamento

Figura 16 - Cisalhamento da laje de concreto.

\section{Análise dos Componentes de Concreto de Conectores Crestbond Contínuos}

Neste item são analisadas vigas com conectores Crestbond CR56b contínuos submetidos somente à cisalhamento (Figura 17a). Nessa investigação foram estudados conectores com 3, 6, 9 e 12 componentes de concreto, com o objetivo de verificar se a capacidade resistente do componente permaneceria inalterada apesar do aumento do comprimento.

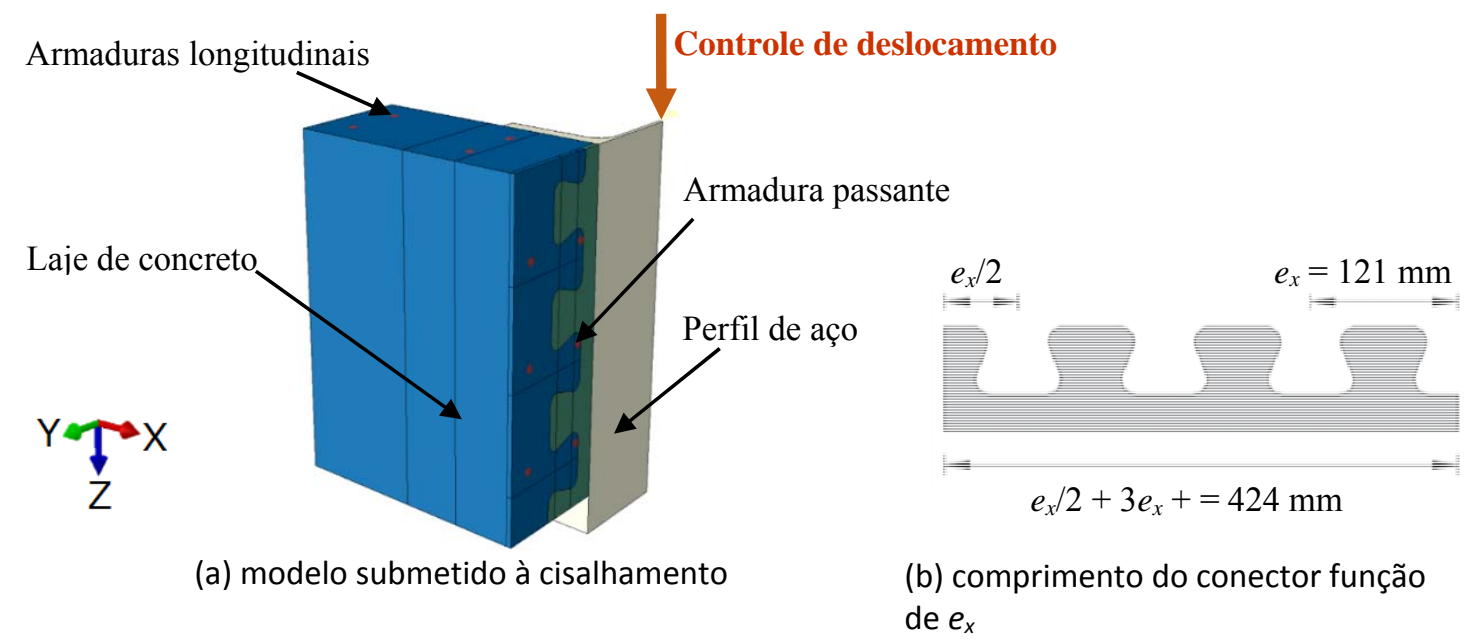

Figura 17 - Modelo com Crestond contínuos com 3 componentes de concreto. 
Os modelos possuíam as mesmas características mecânicas dos modelos apresentados no Item 5 , com exceção da resistência do concreto $\left(f_{c}\right)$, agora igual a $45 \mathrm{MPa}$. Para os componentes dos conectores, eram mantidas as dimensões que foram representadas anteriormente na Figura 6a, variando somente o comprimento total do conector. Esse comprimento era função do passo do conector $\left(e_{x}\right)$ igual a $121 \mathrm{~mm}$ (Figura 17b). As lajes de concreto possuíam barras de armadura passante com diâmetro de $10 \mathrm{~mm}$.

Nos modelos com 12 componentes de concreto, houve dificuldade de convergência quando se utilizou o método de convergência Dynamic Implicit do Abaqus (Hibitt et al., 2014), provavelmente devido ao grande número de interações de contato presentes nesses modelos. Para contornar o problema e manter uma certa padronização na modelagem numérica, foi utilizado o método de convergência Dynamic Explicit. Nesse método, assim como no Dynamic Implicit, análises quase-estática podem ser realizadas. Nessas simulações, foram utilizados elementos de integração reduzida C3D8R, pois o custo computacional para elementos de integração completa, para o Dynamic Explicit, é consideravelmente mais elevado. (Figura 18).

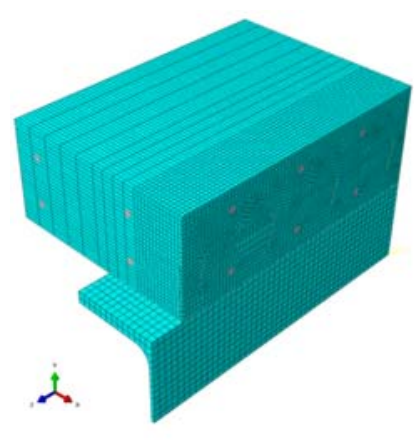

(a) 3 componentes de concreto

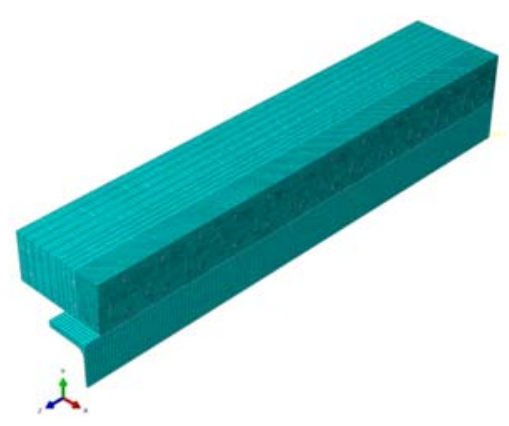

(b) 12 componentes de concreto.

Figura 18 - Malha de elementos finitos utilizada nos modelos com Crestbond contínuo.

Na Figura 19 são apresentados diagramas força versus deslizamento relativo obtidos na análise numérica. Na Figura 19a podem ser vistas as curvas dos modelos considerando a força total aplicada e na Figura 19b as curvas considerando a força total aplicada dividida pela quantidade de componentes de concreto. Observando-se esses diagramas, conclui-se que a capacidade média de um componente de concreto permanece inalterada, mesmo aumentando-se o comprimento total do conector. 


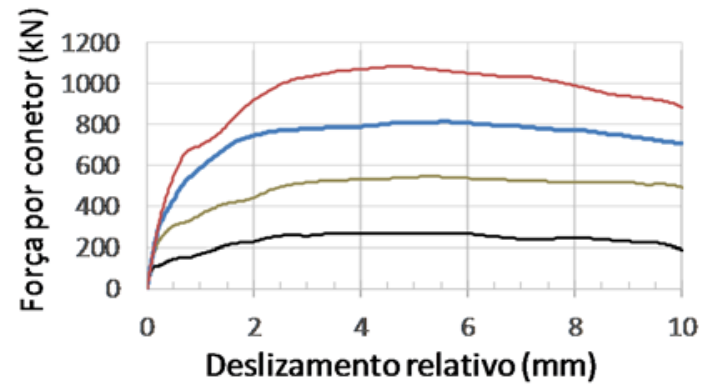

$\begin{array}{ll}-3 \text { componentes } & -6 \text { componentes } \\ -9 \text { componentes } & -12 \text { componentes }\end{array}$

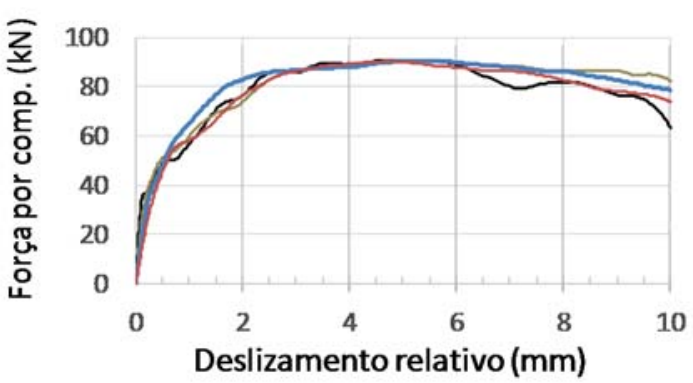

-3 componentes $\quad-6$ componentes

-9 componentes - 12 componentes pela a quantidade de componentes de concreto

Figura 19 - Curvas força versus deslizamento.

Nas Figuras 20a e 20b, são apresentados os danos à tração e a compressão, respectivamente, para o modelo com 12 componentes, no momento em que ocorre o incremento de força máxima. Nota-se que os componentes de concreto sofrem dano à compressão de forma homogênea. Contudo, ao observar o dano à tração na laje, verifica-se que a perda de rigidez à tração nos componentes de concreto é ligeiramente menor naqueles situados próximo à seção em que é aplicado o carregamento.

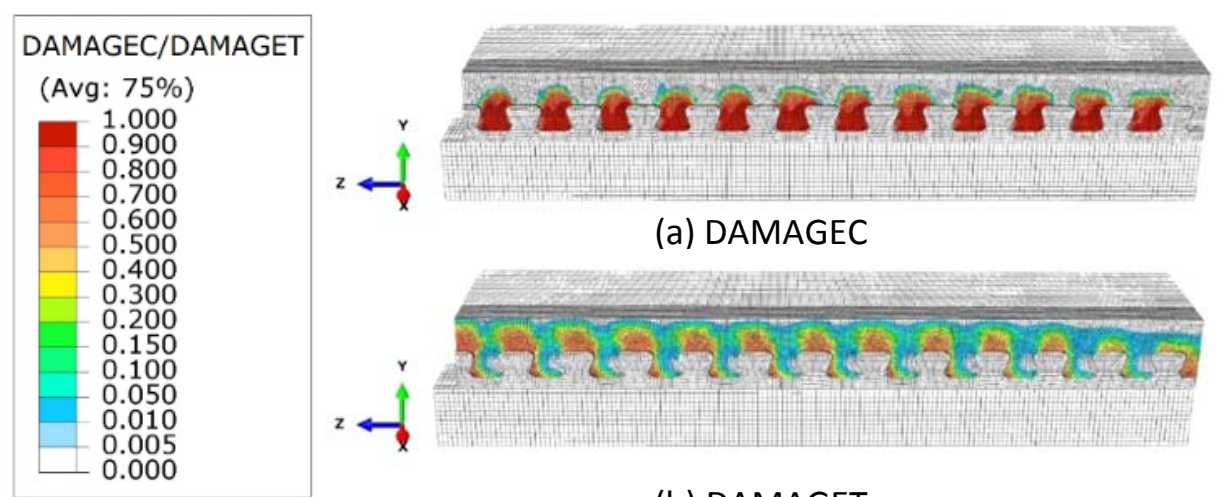

\section{(b) DAMAGET}

Figura 20 - Variáveis de dano no incremento de força máxima.

\section{Conclusões}

Neste trabalho, foi realizada uma investigação sobre o comportamento de conectores Crestbond aplicados em vigas mistas de aço e concreto. Para tal, foram realizadas simulações numéricas utilizando o software comercial de elementos finitos Abaqus (Hibitt et al., 2014). O modelo numérico representou de forma satisfatória o comportamento dos modelos experimentais de cisalhamento padrão realizados por Veríssimo (2007). Constatou-se que os modelos experimentais e numéricos rompiam de forma semelhante, com o surgimento de fissuras localizadas na linha de ação dos 
conectores e nas extremidades das lajes, caracterizando como estado-limite último o cisalhamento da laje de concreto. Observou-se também que quando o conector Crestbond é utilizado de forma contínua, a capacidade média de um componente de concreto para resistir a esforços de cisalhamento permanece a mesma, independentemente do número de componentes.

É oportuno salientar que outros estados-limites podem ocorrer nos ensaios de cisalhamento, como a ruptura do conector e o pry-out. O primeiro pode ocorrer quando se utilizam conectores de menor espessura ou lajes com concretos mais resistentes e, o segundo, principalmente em situações que a laje de concreto seja pouco espessa, dependendo da taxa de armadura transversal.

\section{Agradecimentos}

Os autores agradecem os apoios concedido pela CAPES (Coordenação de Aperfeiçoamento de Pessoal de Nível Superior), CNPq (Conselho Nacional de Desenvolvimento Científico e Tecnológico) e FAPEMIG (Fundação de Amparo à Pesquisa do Estado de Minas Gerais).

\section{Referências bibliográficas}

Aguiar, O. P. Estudo do Comportamento de Conectores Crestbond em Pilares Mistos Tubulares Preenchidos com Concreto. Dissertação de Mestrado - Escola de Engenharia, Universidade Federal de Minas Gerais (UFMG), Belo Horizonte, Brasil, 2015.

Berthellemy, J.; Lorenc, W.; Mensinger, M; Ndogmo, J; Seidl, G. Zum Tragverhalten von Verbunddübeln - Teil 2. Stahlbau, v.80(4), p. 256-267, 2011.

Biegus, A.; Lorenc, W. Development of Shear Connections in Steel-Concrete Composite Structures. Civil And Environmental Engineering Reports, v.15(4), p. 23-32, 2015.

Cardoso, H. S. Conetores Crestbond Aplicados em Pilares Tubulares de Aço Preenchidos com Concreto. Projeto de Tese para Obtenção do Título de Doutor em Engenharia de Estruturas Escola de Engenharia, Universidade Federal de Minas Gerais (UFMG), Belo Horizonte, 2016.

Dutra, C. M. Estudo do Comportamento Estrutural do Conector Crestbond Considerando Variações Geométricas e Mecânicas. Dissertação de Mestrado - Universidade Federal de Viçosa (UFV), Viçosa, Brasil, 2014.

European Committee for Standardization - EN 1992-1-1:2004. Eurocode 2: Design of Concrete Structures, Part 1.1: General Rules and Rules for Buildings. Bruxelas, Bélgica, 2004.

European Committee for Standardization - EN 1994-1-1:2004. Eurocode 4: Design of Composite Steel and Concrete Structures, Part 1.1: General Rules and Rules for Buildings. Bruxelas, Bélgica, 2004.

Feldmann, M.; Kopp, M.; Park, D. Composite Dowels as Shear Connectors for Composite Beams - Background to the German Technical Approval. Steel Construction, v.9(2), p. 80-88, 2016. 
Hibitt, Karlsson, Sorensen. Abaqus Online Documentation. Version 6.14, Dassault Systèmes, SIMULIA, 2014.

Kim, S. E.; Nguyen, H. T. Finite Element Modeling and Analysis of a Hybrid Steel-PSC Beam Connection. Engineering Structures, v. 32(9), p. 2557-2569, 2010.

Kraus, D.; Wurzer, O. Nonlinear Finite-Element Analysis of Concrete Dowels. Computers \& Structures, v.64(5-6), p. 1271-1279, 1997.

Lorenc, W. The Model for a General Composite Section Resulting from the Introduction of Composite Dowels. Steel Construction, v.10(2), p. 154 - 167, 2017.

Lorenc, W.; Kożuch, M.; Rowiński, S. The Behaviour of Puzzle-Shaped Composite Dowels - Part I. Journal of Constructional Steel Research, v.101, p. 482-499, 2014.

Lorenc, W.; Kubica, E.; Kożuch, M. Testing Procedures in Evaluation of Resistance of Innovative Shear Connection with Composite Dowels. Archives of Civil and Mechanical Engineering, v.10(3), p. 51-63, 2010.

Medberry, S. B.; Shahrooz, B. M. Perfobond Shear Connector for Composite Construction. Engineering Journal, American Institute of Steel Construction (AISC), v.39, p. 2-12, 2002.

Pavlović, M.; Marković, Z.; Veljković, M.; Buđevac, D. Bolted Shear Connectors vs. Headed Studs Behaviour in Push-Out Tests. Journal of Constructional Steel Research, v.88, p. 134-149, 2013.

Petrauski, M. C. Simulação Numérica do Comportamento de Vigas Mistas de Aço e Concreto com Conectores Crestbond. Dissertação de Mestrado - Universidade Federal de Viçosa (UFV), Viçosa, Brasil, 2016.

Prado, L. F. P.; Caldas, R. B. Influência do Conector Crestbond na Distribuição de Temperaturas em Pilares Mistos Tubulares Preenchidos com Concreto em Situação de Incêndio. In: VII Congresso Latino-americano da. Construção Metálica, São Paulo, 2016.

Schmitt, V; Seidl, G; Hever, M; Zapfe. Verbundbrücke Pöcking - Innovative VFT-Träger mit Betondübeln. Stahlbau v.73(6), p. 387-393, 2004.

Seidl, G.; Viefhues, E.; Berthellemy, J.; Mangerig, I.; Wagner, R.; Lorenc, W.; Kozuch, M.; Franssen, J-M.; Janssen, D; Ikäheimonen, J.; Lundmark, R.; Hechler, O; Popa, N. Preco-Beam: Prefabricated Enduring Composite Beams Based on Innovative Shear Transmission. Research Fund for Coal and Steel - Final Report. Luxemburgo, Luxemburgo, 2013a.

Seidl, G.; Hoyer, O.; Zanon, R.; Popa, N.; Lorenc, W, Rowiński, S.; Kożuch, M.; Franssen, J-F., Fohn, T.; Quinchia, J. P.; Carrasco, C. H.; Farhang, A.; Nüsse, G. PRECO+: Prefabricated Enduring Composite Beams Based on Innovative Shear Transmission. Research Fund for Coal and Steel - Final Report. Berlin, Alemanha, 2013b.

Silva, M.A.P. Modelos Semiempíricos para a Estimativa da Capacidade Resistente de Conectores de Cisalhamento Crestbond e Perfobond. Dissertação de Mestrado - Universidade Federal de Viçosa (UFV), Viçosa, Brasil, 2011.

Silva, H. P. Simulação Numérica do Comportamento de Conectores de Cisalhamento tipo Crestbond. Dissertação de Mestrado - Universidade Federal de Viçosa (UFV), Viçosa, Brasil, 2013.

Veríssimo, G. S. Desenvolvimento de um Conector de Cisalhamento em Chapa Dentada para Estruturas Mistas de Aço e Concreto e Estudo do seu Comportamento. Tese de Doutorado Escola de Engenharia, Universidade Federal de Minas Gerais (UFMG), Belo Horizonte, Brasil, 2007.

Veríssimo, G. S.; Paes, J. L. R.; Valente, I.; Cruz, P. J. S.; Fakury, R. H. Design and Experimental Analysis of a New Shear Connector for Steel and Concrete Composite Structures. In: 3rd International Conference on Bridge Maintenance, Safety and Management, v. 1, 2006. 